\title{
Carbonyl sulfide-mediated synthesis of peptides with amino acid ionic liquids
}

\author{
Ming Chen*†, and Xihan $\mathrm{Yu}^{\ddagger}$ \\ 'Laboratory of Natural Peptide Chemistry, College of Life Science, Yan'an University, Shendi Road \\ 580, Yan'an 716000, China. \\ ${ }^{\ddagger}$ College of Pharmacy, East China University of Science and Technology, Meilong Road 130, \\ Shanghai 200237, China.
}

\begin{abstract}
Carbonyl sulfide (OCS), the component of volcanic emission, has been found to induce the condensation of amino acids under simulated primordial earth conditions. However, the applications of OCS in peptide chemical synthesis is still limited by their heterogeneities and low efficiencies. We herein report an OCS-mediated approach for solid-phase peptide synthesis using amino acid ionic liquids as recyclable reactants. The coupling reactions required no base and solvent and was completed in minutes at room temperature. The applicability and sustainability of this approach were demonstrated by the facile syntheses of peptides with remarkably high yields.
\end{abstract}

It has been surmised in 1971 that the carbonyl sulfide (OCS) might play a central role in peptide formation at the initial stage of abiogenesis. ${ }^{1}$ The results of subsequent studies in prebiotic chemistry suggested that OCS reacted with $\alpha$-amino acids to afford $N$-carboxyanhydrides (NCA), which could undergo the further condensation with amino acids to form peptide bonds in alkaline buffer solution. ${ }^{2,3}$ However, the peptide product was produced rather slowly (only $6.8 \%$ yield of dipeptide in 56 hours). Even under optimized conditions using potassium ferricyanide or lead chloride as catalyst, only trace amount of tri- and tetrapeptides were produced and the yield of dipeptide was still less than 50\%.3 Thus, the efficiency of OCS-mediated approach is far from meeting the minimum requirements of a sequential peptide synthesis.

In our previous work, native chemical ligation reactions were efficiently achieved in an anhydrous imidazolium-based ionic liquid without any additive. ${ }^{4}$ This finding inspired us to replace the amino acids with the imidazolium-based amino acid ionic liquids (AAILs) ${ }^{5,6}$ in the OCS-mediated peptide synthesis. We expected that AAILs could enhance the coupling reactions in peptide synthesis by providing an extremely high concentration of reactants. Moreover, the experimental procedure of solid-phase peptide synthesis (SPPS) may be simplified if the AAILs could efficiently captured OCS, as the ionic liquids are deemed to be an ideal $\mathrm{CO}_{2}$ solvent.,

A series of novel AAILs were first prepared through a simple neutralization of commercially available fluorenylmethyloxycarbonyl (Fmoc)-protected amino acids with 1-ethyl-3-methylimidazolium hydroxide ([emim][OH]). To avoid the possible Fmoc-cleavage, the highly diluted aqueous solution of [emim][OH] was added dropwise to a slightly excess equimolar amino acid in a tetrahydrofuran (THF)-water mixed solution at $10{ }^{\circ} \mathrm{C}$ (Scheme 1). On evaporation of the solvent, colorless to pale yellow liquid AAILs were obtained at room temperature. The proposed structures of the Fmoc-AAILs were confirmed by NMR and elemental analysis (see Supporting Information). All the Fmoc-AAILs are miscible in acetonitrile, methanol, and dimethylformamide (DMF), but immiscible in diethyl ether at room temperature. Most of Fmoc-AAILs were poorly or very poorly soluble in water except the aqueoussoluble [emim][Gly].

Scheme 1. Synthesis of protected AAILs by neutralization reactions 


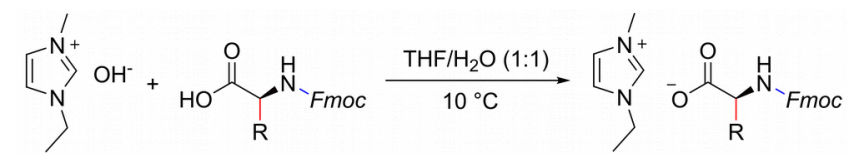

[emim][Fmoc-Gly], R= H [emim] [Fmoc-Ile], $\mathrm{R}=$ = [emim][Fmoc-Val], $\mathrm{R}=$ [emim][Fmoc-Trp(Boc)], $\mathrm{R}=\mathrm{N}-\mathrm{BoC}$ [emim][Fmoc-Asp(OtBu)], $\mathrm{R}=\prod_{\mathrm{O}}^{\mathrm{O}} \mathrm{OtBu}$

[emim][Fmoc-Glu(OtBu)],<smiles>[R]C(C)(C)CCCC(=O)OCCC</smiles>

[emim][Fmoc-Lys(Boc)],<smiles>[R]C(C)(C)CCCCNC(=O)OC(C)(C)C</smiles>

[emim][Fmoc-Met], R=

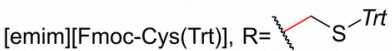

[emim] [Fmoc-Ser(tBu)], $\mathrm{R}=\mathrm{O}^{-t B u}$

[emim][Fmoc-Thr(tBu)], R= ${ }_{0}^{-t B u}$
[emim][Fmoc-Ala], $\mathrm{R}=\mathrm{Me}$ [emim][Fmoc-Leu], $\mathrm{R}=$ 位 [emim] [Fmoc-Phe], $\mathrm{R}=$ $\mathrm{Ph}$ [emim][Fmoc-Tyr(tBu)]<smiles>[R]C(C)(C)CCc1ccc(OCCC)cc1</smiles>

[emim][Fmoc-His(Trt)],<smiles>[R]C(C)Cc1cn([Tl])cn1</smiles>

[emim][Fmoc-Asn(Trt)], $\mathrm{R}=\sum_{\mathrm{O}}^{\mathrm{H}} \mathrm{m^{ \textrm {H } }} \mathrm{Tr}$

[emim][Fmoc-GIn(Trt)],<smiles>[R]C(C)(C)CCC(=O)N[Tl]</smiles>

[emim][Fmoc-Arg(Pbf)],<smiles>[R]C(C)(C)CCCNC(=N)NC(=O)O</smiles>

[emim][Fmoc-Pro],
Next, the thermophysical properties of the FmocAAILs were investigated by thermogravimetric analysis (TGA) and differential scanning calorimetry (DSC) (Table 1).

Table 1. Thermal properties and viscosities of the Fmoc-AAILs

\begin{tabular}{|c|c|c|}
\hline $\begin{array}{l}\text { entr } \\
y\end{array}$ & $\begin{array}{lll}\text { anion } & \text { of } & \mathrm{T}_{\mathrm{g}} \\
\text { AAIL } & & \left({ }^{\circ} \mathrm{C}\right)^{\mathrm{a}}\end{array}$ & $\begin{array}{ll}\mathrm{T}_{\mathrm{d}} & \eta / \eta^{\prime}([\mathrm{CP}])^{\mathrm{c}} \\
\left({ }^{\circ} \mathrm{C}\right)^{\mathrm{b}} & \end{array}$ \\
\hline 1 & [Fmoc-Gly] & \\
\hline 2 & [Fmoc-Ala] & \\
\hline 3 & [Fmoc-Val] & \\
\hline 4 & [Fmoc-Leu] & \\
\hline 5 & [Fmoc-Ile] & \\
\hline 6 & [Fmoc-Phe] & \\
\hline 7 & [Fmoc-Trp(Boc)] & \\
\hline 8 & [Fmoc-Tyr(tBu)] & \\
\hline 9 & [Fmoc-Asp(tBu)] & \\
\hline 10 & [Fmoc-His(Trt)] & \\
\hline 11 & [Fmoc-Asn(Trt)] & \\
\hline 12 & [Fmoc-Glu(tBu)] & \\
\hline 13 & [Fmoc-Lys(Boc)] & \\
\hline 14 & [Fmoc-Gln(Trt)] & \\
\hline 15 & [Fmoc-Met] & \\
\hline 16 & [Fmoc-Arg(Pbf)] & \\
\hline 17 & [Fmoc-Ser(tBu)] & \\
\hline 18 & [Fmoc-Thr(tBu)] & \\
\hline 19 & [Fmoc-Cys(Trt)] & \\
\hline
\end{tabular}

Next, the resulting ionic liquids were examined as solvents for OCS capture by using gravimetric technique at atmospheric pressure. Figure 1 shows that each mole of alkaline buffer solution could absorb only approximately 0.007 mole OCS, ${ }^{3}$ while the mole ratios of OCS to different AAILs varied in a range of $0.11-0.16$. Thus, the AAILs were supposed to be effective for OCS-capture without addition of base and thereby may provide mild conditions for peptide synthesis.

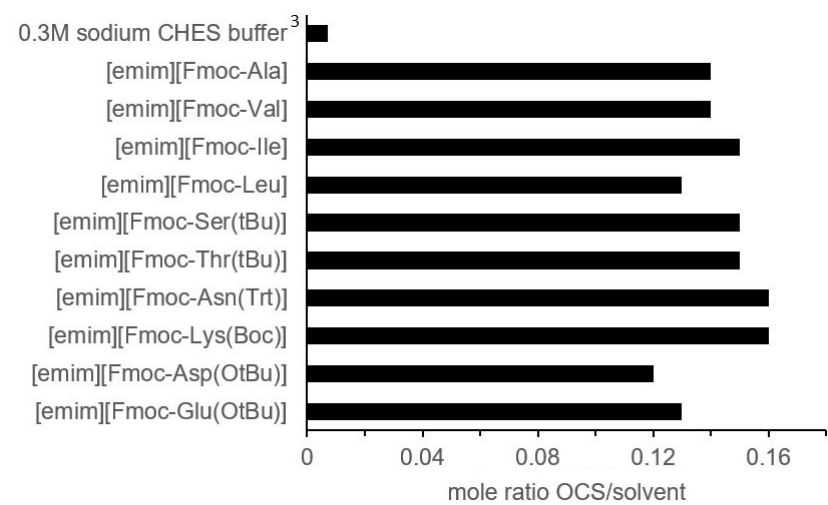

Figure 1. Molar ratios of absorbed OCS to aqueous buffer solution and protected AAILs.

Here we describe an OCS-mediated method for Fmoc solid-phase peptide synthesis using AAILs (OCS-mediated SPPS, Scheme 2). Preloaded Wang-ChemMatrix ${ }^{\circledR}$ resin is used as starting material due to its superior swelling property in both dimethylformamide (DMF) and imidazoliumbased ionic liquid. ${ }^{9}$ The peptide-chain assembly was elongated by OCS-mediated SPPS. In each coupling/deprotection cycle, the desired OCSsaturated AAIL is directly mixed with DMF-swollen resin without additional reagent or solvent and Fmoc group is then removed using $20 \%$ piperidine in DMF. The peptide is finally cleaved from the resin by treatment with a trifluoroacetic acid (TFA) cocktail.

\section{Scheme 2. Schematic diagram for the OCS-mediated SPPS}

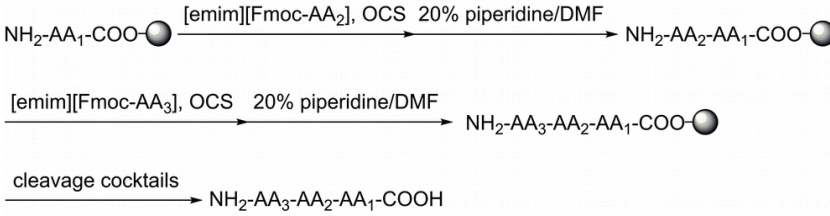

To assess the practical use of the new method, a model tetrapeptide, Thr-Asn-Ser-Tyr, was prepared under various conditions. The peptide synthesis using OCS-saturated AAILs (Table 1, entry 2) significantly reduced the coupling time and resulted in much higher yield than conventional SPPS method (entry 1). A racemization study for the OCS-mediated SPPS was performed through determination of stereoisomers of the intermediate peptide Asn-Ser-Tyr by reversedphase high performance liquid chromatography (RP-HPLC), and no racemization was detected (see $\mathrm{SI})$. We encountered complete coupling failure in 
absence of OCS (entry 3). This fact indicates that OCS is essential in the synthesis using AAILs. However, increasing the temperature did not enhance the OCS-mediated SPPS but caused a serious deamidation of ionic liquid [emim][FmocAsn(Trt)] (entry 4, see SI). It was also found that the peptide formation in OCS-mediated SPPS was inhibited when water was introduced in the reaction system (entry 5 ).

Table 1. Syntheses of Thr-Asn-Ser-Tyr by conventional and OCS-mediated SPPS methods

$\begin{array}{cccccc}\begin{array}{c}\text { entr } \\ y\end{array} & \text { reactants } & \begin{array}{c}\text { additives, } \\ \text { solvent }\end{array} & \begin{array}{c}\text { time } \\ a \\ (\min \\ )\end{array} & \begin{array}{c}\mathrm{T} \\ \left({ }^{\circ} \mathrm{C}\right)\end{array} & \begin{array}{c}\text { yiel } \\ \mathrm{d}^{b} \\ (\%)\end{array} \\ 1 & \begin{array}{c}\text { amino } \\ \text { acids }\end{array} & \begin{array}{c}\text { HATU, } \\ \text { DIEA }^{d}, \text { DMF }\end{array} & 50^{e} & 25 & 68.6 \\ 2 & \text { AAILs } & - & 45 & 25 & 0.0 \\ 3 & \text { AAILs } & \text { OCS }^{f} & 5 & 25 & 93.2 \\ 4 & \text { AAILs } & \text { OCS }^{f} & 15 & 60 & 0.0^{g} \\ 5 & \text { AAILs } & \text { OCS }^{f}, \mathrm{H}_{2} \mathrm{O}^{h} & 45 & 25 & 17.6\end{array}$

${ }^{a}$ Coupling time. ${ }^{b}$ Isolated yield based on the loading of the resin. 'Fourfold excess of Fmocamino acids relative to the resin. ${ }^{d}$ Fourfold excess of 1 -[bis(dimethylamino)methylene]-1H-1,2,3triazolo[4,5-b]pyridinium

3-oxide hexafluorophosphate (HATU) and eightfold excess of $\mathrm{N}, \mathrm{N}$-diisopropylethylamine (DIEA) relative to the resin. ${ }^{e} 5-m i n$ pre-activation time included. ${ }^{f}$ OCS gas bubbled into AAIL before coupling. ${ }^{9} \mathrm{~A}$ brownred highly viscous curd arising upon heating. ${ }^{h} 10 \%$ v/v water in AAIL.

Encouraged by the above results, we further used Thymosin $\alpha 1$, a 28-mer bioactive peptide (Figure $2 \mathrm{~A}),{ }^{10,11}$ to validate OCS-mediated SPPS method for long peptide synthesis. Thymosin $\alpha 1$ was considered to be a 'difficult' peptide since its sequence contains consecutive $\beta$-branched amino acids, which can lead to aggregation in peptide synthesis. ${ }^{12,13}$ Synthesis of Thymosin $\alpha 1$ was carried out on a H-Asn(Trt)-Wang-ChemMatrix resin using OCS-saturated AAILs. After N-terminal acylation and cleavage from the resin, a crude peptide was obtained in good purity (86.7\%).

Besides the synthetic efficiency, another important issue for OCS-mediated SPPS is the reusability of the protected AAILs. The used AAIL was washed out with DMF after each coupling step, and then cleaned up by an ether wash. However, the yield gradually dropped from the first reuse of the recycled AAILs (Figure 2B). The yield reduction is probably due to the recycling process, which caused OCS loss from the ionic liquid. Thus, we treated the recycled AAILs with the flow of OCS to recover their OCS contents. We found that, even after five runs of recycling, the 'reactivated' AAILs could still afford the peptide product in comparable yield $(25.0 \%)$ with that obtained by the freshly prepared AAILs $(26.5 \%$, Figure 2B).
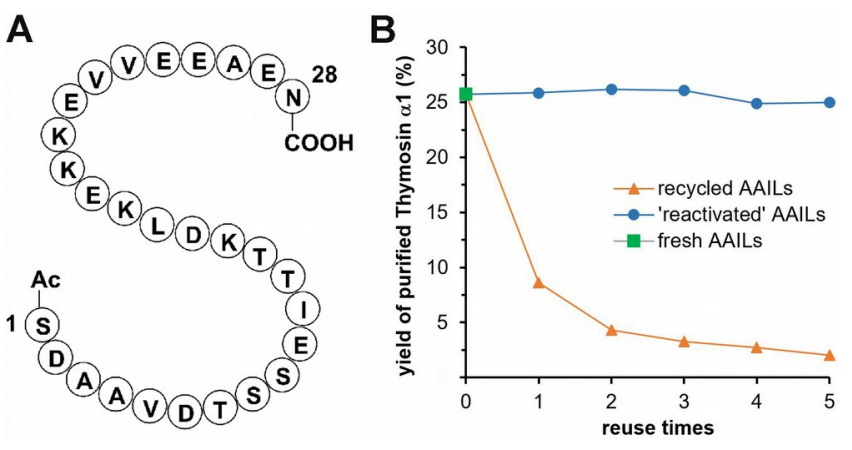

Figure 2. A) Sequence of Thymosin $\alpha 1$. B) Effect of reusability of AAILs on the yield of Thymosin $\alpha 1$ synthesis.

Based on the previous studies of the mechanism for prebiotic peptide formation, ${ }^{3,14}$ two possible pathways were proposed to explain the enhancement effect of OCS on peptide formation using AAILs. In the first mechanism (Scheme 3A), the imidazolium cation assists the OCS-mediated conversion of the anion of AAIL $\mathbf{1}$ to a C-terminal amino acid thiocarboxylate $\mathbf{2 ,},{ }^{15,16}$ which is oxidized to a dimeric thiocarboxylate $\mathbf{3}$ in ionic liquid. A protected dipeptide attached to the resin $\mathbf{5}$ arises by the coupling of resin-bound amino acid 4 with 2. The other possibility (Scheme 3B) is that OCS reacts with 4 to form an amino acid thiocarbamate $\mathbf{6}^{17}$ The oxidative coupling between $\mathbf{2}$ and $\mathbf{6}$ gives intermediate $\mathbf{7}$, which is converted to peptide $\mathbf{5}$ through a five-membered transition state.

\section{Scheme 3. Hypothetical mechanisms for the OCS-mediated SPPS}

A

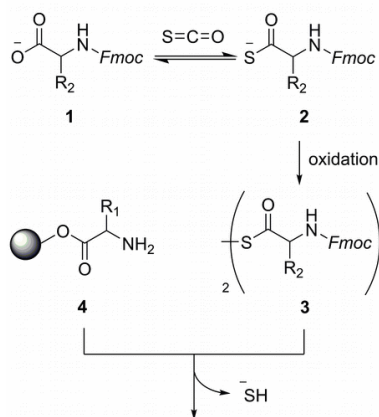

B

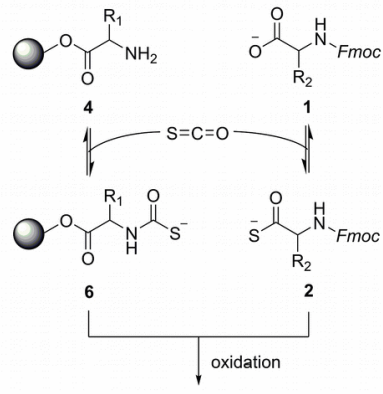

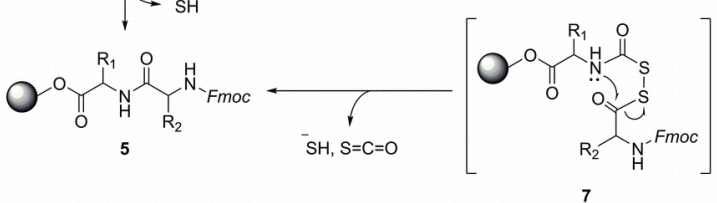

To investigate the possible mechanisms of OCSmediated SPPS, we performed several model tests (Table 2), in which L-phenylalanine or Lphenylalanine thiocarbamate reacted with potassium acetate or potassium thioacetate in ionic liquid 1-butyl-3-methylimidazolium tetrafluoroborate $\left([\mathrm{bmim}]\left[\mathrm{BF}_{4}\right]\right)$, to generate an acetylphenylalanine. It seemed that the presence of excess thioacetate salt enhanced the reactions (entries 3), yet the reactions involving thiocarbamate took place at very slow rate (entry $2,5)$. We also found that the yield decreased 
markedly when one equivalent of thioacetate salt was used (entry 4). These findings coincide well with the experimental regularity reported by Orgel et al.. ${ }^{14}$ Thus, even we cannot completely exclude the possibility of mechanism $B$, the results strongly suggest that the mechanism A should play the main role in the peptide bond formation in AAILs. Moreover, to establish the influences of cations and anions of ionic liquids, 1-ethyl-3methyl-imidazolium-trifluormethansulfonat ([emim][Otf]) and 1-butyl-3- methypyridinium tetrafluoroborate ([BMPy][BF $]$ ) were individually applied for the $N$-acetyl-L-phenylalanine synthesis. The amide product was generated only in imidazolium-based ionic liquids (entries 6,7). It probably indicates that the existence of imidazolium cation is a leading factor for a successful OCS-mediated peptide formation.

Table 2. Synthesis of $N$-acetyl-L-phenylalanine

\begin{tabular}{|c|c|c|c|c|c|}
\hline $\begin{array}{l}\text { entr } \\
\mathrm{y}\end{array}$ & $\mathrm{R}$ & $x$ & $\begin{array}{l}\text { rati } \\
0^{a}\end{array}$ & $\begin{array}{l}\text { additive, } \\
\text { solvent }\end{array}$ & $\begin{array}{l}\text { yield } \\
(\%)^{b}\end{array}$ \\
\hline 1 & $-\mathrm{H}$ & $\mathrm{O}$ & $1: 3$ & {$[\mathrm{bmim}]\left[\mathrm{BF}_{4}\right]$} & n.d. \\
\hline 2 & $\bar{C}(\mathrm{O}) \mathrm{S}$ & $\mathrm{O}$ & $1: 3$ & {$[\mathrm{bmim}]\left[\mathrm{BF}_{4}\right]$} & 4.0 \\
\hline 3 & $-\mathrm{H}$ & $\mathrm{S}$ & $1: 3$ & {$[\mathrm{bmim}]\left[\mathrm{BF}_{4}\right]$} & 85.3 \\
\hline 4 & $-\mathrm{H}$ & $S$ & $1: 1$ & {$[\mathrm{bmim}]\left[\mathrm{BF}_{4}\right]$} & 51.5 \\
\hline 5 & $\mathrm{C}(\mathrm{O}) \mathrm{S}$ & $\mathrm{S}$ & $1: 3$ & {$[\mathrm{bmim}]\left[\mathrm{BF}_{4}\right]$} & 7.1 \\
\hline 6 & $-\mathrm{H}$ & $\mathrm{S}$ & $1: 3$ & [emim][Otf] & 85.2 \\
\hline 7 & $-\mathrm{H}$ & $\mathrm{S}$ & $1: 3$ & {$[\mathrm{BMPy}]\left[\mathrm{BF}_{4}\right]$} & n.d. \\
\hline
\end{tabular}

${ }^{a}$ Equivalence ratio of L-phenylalanine or Lphenylalanine thiocarbamate to potassium acetate or potassium thioacetate. ${ }^{b}$ Yield at $5 \mathrm{~min}$ calculated from peak area in reverse phase HPLC. ${ }^{c}$ OCS gas bubbled into ionic liquid before reaction.

In conclusion, we have reported a sustainable and easy-operated method for the OCS-mediated SPPS in neat AAILs. The use of AAILs provides outstanding reaction efficiency and mild, solventfree conditions, which extend the application of prebiotic peptide formation to stepwise peptide synthesis. Taking the advantages of this method, we are currently dedicated to developing a fully automated approach for the OCS-mediated SPPS, which might be a meaningful innovation in peptide production.

\section{ASSOCIATED CONTENT}

\section{Supporting Information}

The Supporting Information is available free of charge on the ACS Publications website at DOI: .

General information on experimental procedures, HPLC, MS and NMR spectra (PDF)

\section{AUTHOR INFORMATION}

\section{Corresponding Author}

mingchen@uni-bonn.de

\section{Present Addresses}

Jiang Pu Road 740-7, Shanghai 200082, China

\section{Notes}

The authors declare no competing financial interests.

\section{ACKNOWLEDGMENT}

We appreciate Dr. Martin Schlesinger (University Bonn) for proofreading the article. The Research Fund of the European Patent Organization and the State Intellectual Property Office of China are also acknowledged for partial financial support.

\section{REFERENCES}

1. Seyferth, D.; Marmor, R. S.; Hilbert, P. Reactions of Dimethylphosphono-Substituted Diazoalkanes. (MeO)2P(O)CR Transfer to Olefins and 1,3-Dipolar Additions of $(\mathrm{MeO}) 2 \mathrm{P}(\mathrm{O}) \mathrm{C}(\mathrm{N} 2) \mathrm{R}$. J. Org. Chem. 1971, 36 (10), 1379-1386.

2. Katakai, R.; Nakayama, Y. Peptide Synthesis Using o-Nitrophenylsulfenyl $N$-Carboxy $\alpha$-Amino Acid Anhydrides. Sequential oligopeptides Having Alternate $\gamma$-Methyl L-Glutamyl and L-Phenylalanyl Residues. Biopolymers 1976, 15 (4), 747-755.

3. Leman, L. Carbonyl Sulfide-Mediated Prebiotic Formation of Peptides. Science 2004, 306 (5694), 283-286.

4. Kühl, T.; Chen, M.; Teichmann, K.; Stark, A.; Imhof, D. Ionic Liquid 1-Ethyl-3-Methylimidazolium Acetate: An Attractive Solvent for Native Chemical Ligation of Peptides. Tetrahedron Lett. 2014, 55 (27), 3658-3662.

5. Fukumoto, K.; Yoshizawa, M.; Ohno, H. Room Temperature Ionic Liquids from 20 Natural Amino Acids. J. Am. Chem. Soc. 2005, 127 (8), 23982399.

6. Ohno, H.; Fukumoto, K. Amino Acid Ionic Liquids. Acc. Chem. Res. 2007, 40 (11), 1122-1129.

7. Hasib-ur-Rahman, M.; Siaj, M.; Larachi, F. Ionic Liquids for $\mathrm{CO}_{2}$ Capture-Development and Progress. Chem. Eng. Process. Process Intensif. 2010, 49 (4), 313-322.

8. Cadena, C.; Anthony, J. L.; Shah, J. K.; Morrow, T. I.; Brennecke, J. F.; Maginn, E. J. Why Is $\mathrm{CO}_{2}$ So Soluble in Imidazolium-Based Ionic Liquids? J. Am. Chem. Soc. 2004, 126 (16), 5300-5308.

9. Lawrenson, S.; North, M.; Peigneguy, F.; Routledge, A. Greener Solvents for Solid-Phase Synthesis. Green Chem. 2017, 19 (4), 952-962.

10. Goldstein, A. L.; Low, T. L.; McAdoo, M.; McClure, J.; Thurman, G. B.; Rossio, J.; Lai, C. Y.; Chang, D.; Wang, S. S.; Harvey, C.; et al. Thymosin Alpha1: Isolation and Sequence Analysis of an Immunologically Active Thymic Polypeptide. Proc. Natl. Acad. Sci. U. S. A. 1977, 74 (2), 725-729.

11. GARACl, E. Thymosin 1: A Historical Overview. Ann. N. Y. Acad. Sci. 2007, 1112 (1), 14-20.

12. García-Ramos, Y.; Giraud, M.; Tulla-Puche, J.; Albericio, F. Optimized Fmoc Solid-Phase Synthesis of Thymosin Al by Side-Chain Anchoring onto a PEG Resin. Biopolymers 2009, 92 (6), 565-572.

13. Paradís-Bas, M.; Tulla-Puche, J.; Albericio, F. The Road to the Synthesis of "Difficult Peptides." Chem. Soc. Rev. 2016, 45 (3), 631-654.

14. Liu, R.; Orgel, L. E. Oxidative Acylation Using Thioacids. Nature 1997, 389 (6646), 52-54. 
15. Cabaço, M. I.; Besnard, M.; Chávez, F. V.; Pinaud, N.; Sebastião, P. J.; Coutinho, J. A. P.; Danten, Y. Understanding Chemical Reactions of $\mathrm{CO}_{2}$ and Its Isoelectronic Molecules with 1-Butyl-3Methylimidazolium Acetate by Changing the Nature of the Cation: The Case of $\mathrm{CS}_{2}$ in 1-Butyl-1Methylpyrrolidinium Acetate Studied by NMR Spectroscopy and Density Funct. J. Chem. Phys. 2014, 140 (24), 244307.

16. Danten, Y.; Cabaço, M. I.; Coutinho, J. A. P.; Pinaud, N.; Besnard, M. DFT Study of the Reaction Mechanisms of Carbon Dioxide and Its Isoelectronic Molecules $\mathrm{CS}_{2}$ and OCS Dissolved in Pyrrolidinium and Imidazolium Acetate Ionic Liquids. J. Phys. Chem. B 2016, 120 (23), 52435254.

17. Ferm, R. J. The Chemistry of Carbonyl Sulfide. Chem. Rev. 1957, 57 (4), 621-640. 
SYNOPSIS TOC
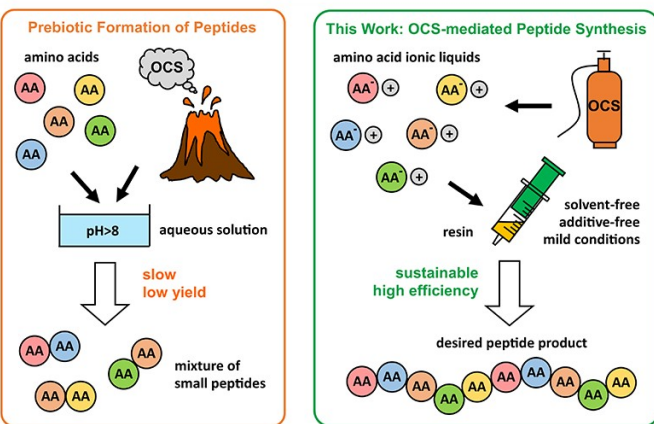